\title{
FRAGMENTAÇÃO SOCIOESPACIAL EM CIDADES DE PORTE MÉDIO
}

\author{
socio-spatial fragmentation on middle-size cities
}

\author{
Clayton Ferreira Dal Pozzo ${ }^{1}$
}

aaAaa

\begin{abstract}
Resumo
O texto analisa a noção de fragmentação socioespacial e as consequências e as especificidades deste processo considerando duas cidades de porte médio no Estado de São Paulo: Marília e São Carlos. A relação entre novas centralidades urbanas e autossegregação, a partir das práticas socioespaciais dos sujeitos autossegregados, têm promovido mudanças nos níveis de integração espacial, as quais tendem a acelerar o processo de ruptura com a continuidade territorial e com a parcela de citadinos submetidos à segregação imposta. Assim, há um aumento nos níveis de neutralização / oposição entre as diferenças que afetam a qualidade e a intensidade da sociabilidade entre os citadinos. Os resultados da pesquisa apontam que, em médio e longo prazo, o modo de vida urbano tende a assumir valores que não levam em conta o diálogo, a unidade territorial e, acima de tudo, a justiça social na cidade.
\end{abstract}

Palavras-chave: Produção do espaço, Fragmentação socioespacial, Cidades de porte médio.

\begin{abstract}
The paper analyses the notion of socio-spatial fragmentation and the consequences and specifics of this process by considering two mid-sized cities in São Paulo State, Marília and São Carlos. The relationship between new urban centralities and auto-segregation, from the socio-spatial practices of auto-segregated subjects, has promoted changes in the levels of spatial integration, which tend to accelerate the process of breaking with territorial continuity and with the dwellers submitted to an imposed segregation. Thus, there is an increase in levels of neutralization / opposition between the differences that affect the quality and intensity of sociability among dwellers. The survey results indicate that, in medium and long term, the urban way of life tends to take values that do not take into account the dialogue, the territorial unity and the social justice in the city.
\end{abstract}

Key words: Production of space, Socio-spatial fragmentation, Middle-size cities.

\begin{abstract}
Resumen
El artículo explora el concepto de fragmentación sócio-espacial y las consecuencias de este proceso en Marilia y São Carlos (dos ciudades de porte médio en el Estado de São Paulo). La relación entre las nuevas centralidades urbanas y auto-segregación que se asocian con prácticas socio-espaciales de los habitantes auto-segregados, han promovido cambios en los niveles de integración espacial. Estos cambios tienden a acelerar la ruptura de la continuidad territorial. Sin embargo, hay un aumento en los niveles de oposición y neutralización entre las diferencias que afectan a la calidad e intensidad de la sociabilidad entre los que viven en la ciudad. Los resultados de la investigación indican que la forma de vida urbana tiende a asumir valores que no mires el diálogo, la unidad territorial y la justicia social en la ciudad.
\end{abstract}

Palabras clave: Producción del espacio, Fragmentación socio-espacial, Ciudades de porte medio.

(1) Doutorando do Programa de Pós-Graduação em Geografia da Universidade Estadual Paulista/Presidente Prudente - Rua Roberto Simonsen, 305, GAsPERR (Docente 1, Sala 25), Centro Universitário, CEP: 19060-900 - Presidente Prudente (SP), Brasil, Tel: (+55 18) 32295375 - cltdp@yahoo.com.br

\section{aaAaa}

Revista da ANPEGE, v. 8, n. 9, p. 29-46, jan./jul. 2012.

ISSN 1679-768 X C 2003, Associação Nacional de Pesquisa e Pós-Graduação em Geografia. Todos os direitos reservados. 


\section{INTRODUÇÃO}

Em geral, os estudos que abordam o conceito de fragmentação socioespacial adotam, como recorte, os espaços urbanos de padrões metropolitanos. Entretanto, há vários indícios que sugerem a necessidade de pesquisas que possibilitem avaliar o aparecimento e as especificidades deste processo, considerando os espaços urbanos de porte médio.

Dois desses indícios tendem a estar relacionados com a proliferação de espaços residenciais fechados e a formação de novos espaços de consumo. Essas formas e processos, articulados a partir das práticas socioespaciais dos sujeitos autossegregados, têm interferido nos níveis de integração espacial, de continuidade territorial e na qualidade de sociabilidade entre os citadinos.

Tendo em vista contribuir com o processo de análise desses indícios (e com as especificidades e consequências da fragmentação socioespacial), duas cidades de porte médio paulistas foram escolhidas, quais sejam, Marília e São Carlos.

Para apresentar os resultados obtidos, o texto foi estruturado em três partes. Essencialmente teórica, na primeira parte, intitulada "Autossegregação, novas centralidades urbanas e práticas socioespaciais", realizamos uma breve contextualização (e sistematização das principais características) da noção de fragmentação socioespacial vinculada aos estudos dos espaços urbanos.

$\mathrm{Na}$ segunda parte, intitulada "Fragmentação socioespacial em espaços urbanos de diferentes portes" aproximamos uma série de resultados de pesquisas empíricas de diversos autores que abordaram o tema de segregação e de fragmentação socioespacial considerando os espaços urbanos latino-americanos de padrões metropolitanos ou de porte médio.

Na terceira parte, intitulada "Fragmentação socioespacial em Marília e São Carlos", apresentamos os principais resultados obtidos com a realização de nossa pesquisa, baseando-se no conjunto de depoimentos e na representação e análise comparativa das práticas socioespaciais dos sujeitos autossegregados nas duas cidades de porte médio pesquisadas.

Esperamos ter recolhido elementos que contribuam com a realização de novas pesquisas e de debates, tendo em vista, esboçar as possibilidades analíticas e de enfrentamento da fragmentação socioespacial no espaço urbano contemporâneo.

\section{AUTOSSEGREGAÇÃO, NOVAS CENTRALIDADES URBANAS E PRÁTICAS SOCIOESPACIAIS}

A autossegregação, enquanto processo de produção e de ocupação dos espaços residenciais fechados, comparece como um dos elementos preponderantes para o advento do fenômeno de fragmentação socioespacial, pois, contribui com o processo de "rompimento da comunicação e do diálogo entre os diferentes segmentos sociais" (SPOSITO, 1996b, p. 74).

De um modo geral, a autossegregação aparece nas cidades de porte médio paulistas, por volta da década de 1970 intensificando-se a partir da década de 1990 e se caracteriza como uma nova opção de moradia para os segmentos de médio a alto poder aquisitivo.

Com a intensificação da autossegregação nessas cidades, a partir da década de 1990 (em substituição à "onda" de verticalização), e quando, de fato, começa a ocorrer um maior número de famílias que se autossegregam, os conteúdos sociais e econômicos da periferia urbana (incluso a formação de novas centralidades urbanas e os processos que caracterizam uma segregação imposta) se diversificam (SPOSITO, 2003b).

Em geral, a segregação imposta é antecedente ao processo de autossegregação e, portanto, contempla um processo mais amplo de reprodução das desigualdades socioespaciais e de rupturas com a diferenciação socioespacial. Nesse sentido, o processo de segregação imposta tende a condicionar, do ponto de vista do habitat urbano, como os mais pobres devem ocupar a cidade.

Diante de uma autossegregação ainda pouco expressiva, remetendo-se, portanto, às décadas anteriores à de 1980, a segregação socioespacial (em termos de segregação imposta) se estabelecia, predominantemente, por uma forma de ocupação da periferia urbana, ainda pouco dispersa e, 
geralmente, dotada de infraestrutura urbana e habitações precárias que se voltaram ao atendimento de moradia das famílias mais pobres.

Nesse sentido, os segmentos de menor poder aquisitivo contemplam um duplo papel, pois, são agentes, mas também, reféns do processo de segregação imposta, devido ao baixo poder de escolha de onde (e como) morar na cidade.

A partir da década de 1990, novas formas e processos urbanos contribuíram para ampliar, não somente, a segregação imposta, mas também, a autossegregação. Ambos os processos permitiram que a segregação socioespacial se tornasse mais explícita e complexa.

De acordo com Corrêa (2005, p. 64), a articulação entre os agentes de produção do espaço urbano, sobretudo, os empreendedores imobiliários e proprietários de glebas urbanas e de terras rurais, em áreas de expansão urbana, podem potencialmente produzir, ou efetivamente concretizar, a autossegregação, ao contemplar/reproduzir a demanda solvável.

Esse movimento expressa-se a partir da implantação, comercialização (com a ajuda do marketing e da venda programada) e ocupação dos espaços residenciais fechados os quais, geralmente, são dotados de infraestrutura de lazer.

Por outro lado, esses mesmos agentes também contribuem para a geração da segregação imposta, quando controlam o mercado de terras e a incorporação imobiliária, garantindo determinado nível de homogeneidade social nas porções de áreas nas quais se localizam, predominantemente, os espaços residenciais fechados e influenciando no processo de assentamento dos demais grupos sociais considerando outras áreas do espaço urbano (CORRÊA, 2005, p. 64).

Neste caso, podemos destacar duas estratégias desses agentes. Primeiramente, a partir da prática de elevação dos preços dos lotes e das regras, no que se refere ao padrão construtivo das habitações no interior dos espaços residenciais fechados e, em segundo lugar, reservando estoques de terras nas áreas que estão no entorno desses empreendimentos.

A "operacionalização" deste controle social intrínseco à autossegregação, nos termos expostos por Corrêa $(2005$, p. 64), pode ser representada a partir da relação entre técnicas, normas e limites materiais e simbólicos, que se adaptam e contribuem para o delineamento de determinado território, objetivando, estrategicamente, orientar o cumprimento de suas funções e designando determinadas formas de uso e de apropriação.

A partir das práticas socioespaciais dos sujeitos autossegregados, este território também tende a se estender a determinados espaços de consumo coletivo, em geral, privados e voltados a atender, sobretudo, demandas dos segmentos sociais de mais alto poder aquisitivo. Em oposição ao centro, esses espaços contribuem com a formação de novas centralidades urbanas e tendem a difundir um maior nível de segmentação socioespacial.

Como tensionamento entre a autossegregação e a segregação imposta, também podemos destacar, apoiando-se em Santos (1990), dois aspectos: $1^{\circ}$ ) as desigualdades no que se refere à mobilidade e acessibilidade urbanas, às quais, não valorizam o encontro entre as diferenças; $2^{\circ}$ ) os investimentos públicos que privilegiam determinadas porções do espaço urbano em detrimento das demais. Em outros termos, o poder público tende a não valorizar a justiça espacial por consequência da prática de implementação de uma seletividade espacial.

Nesse sentido, esboçam-se os primeiros elementos que contribuem com o processo de identificação e caracterização da fragmentação socioespacial no espaço urbano contemporâneo. Meubirouk (2006) sugere que as primeiras utilizações deste termo, aplicado aos estudos da cidade, remontam aos anos de 1960, para explicar os fracionamentos horizontais (descontinuidades territoriais) e verticais (autonomia dos organismos de gestão da cidade, como o processo de municipalização), durante as fases de grande expansão urbana.

A partir da década de 1980, o termo ganhou acepções mais amplas nas Ciências Humanas, ao ser adotado para denotar um fenômeno global de produção de formas socioespaciais descontínuas e "aleatoriamente" dispersas, marcadas por diversas territorialidades que sucedem a ideia de cidade unitária e solidária (MEUBIROUK, 2006). 
No início da década de 1990, o termo também passou a ser usado para explicar a expressão dos efeitos das crises econômicas, dos fracionamentos político-administrativos e da produção de localismos (de clivagem socioeconômica) nas cidades (MEUBIROUK, 2006).

Meubirouk (2006), a partir das considerações de Navez-Bouchanine (2001, p. 61), enfatiza que a expressão socioespacial, qualificadora do termo fragmentação, aparece como designativo das relações entre grupos que se caracterizam pelo conjunto de semelhanças sociais e, em decorrência das formas de uso e da apropriação do espaço urbano, como essas mesmas relações contribuem para reorientar, sobretudo, a partir da dimensão socioeconômica, as lógicas de "localização/concentração" desses mesmos grupos.

Souza (2008, p. 55-58) adverte sobre os cuidados de não se tomar "fragmentação" por "segregação" - ainda que se possam identificar interconexões entre os dois processos - e, muito menos, transformá-lo numa metanarrativa (enquanto proposição conceitual abrangente e totalizadora), evitando incorrer na perda de seu potencial explicativo.

De acordo com Sobarzo e Sposito (2003, p. 41), a segregação socioespacial que se expressa a partir dos interesses de separação e isolamento dos segmentos de mais alto poder aquisitivo, poderia gerar tendências de fragmentação ao promover: rupturas no tecido urbano promovidos pelos muros e pela localização, geralmente periférica e em descontinuidade territorial e; mudanças no processo de representação subjetiva dos sujeitos autossegregados, os quais não seriam mais orientados pela concepção de unidade territorial da cidade.

Os termos segregação e fragmentação, portanto, seriam designativos de processos distintos ainda que o segundo origine-se a partir de novos desdobramentos do primeiro - e complementares, dentro de uma complexa interação, sem haver oposição ou anulação, ressalvados os casos em que o processo de fragmentação empiricamente não se evidencie.

Partindo de outro ponto de vista, Salgueiro (2001) afirma que a fragmentação se opõe à segregação porque a primeira opera em uma microescala de especialização, enquanto que a segunda opera em uma escala mais extensiva ou, em outros termos:

Enquanto a segregação de raiz social era hierárquica, pois traduzia o escalonamento social baseado na divisão tradicional em classes, a nova fragmentação social dos territórios responde a uma diferenciação social dos indivíduos e grupos mais complexa que nem sempre é hierárquica, porque é baseada num leque mais amplo de factores de estratificação [...] (SALGUEIRO, 2001, p. 186).

Salgueiro (2001, p. 186-187) propõe a substituição do conceito de segregação, por fragmentação por entender que a diferença de escala e de natureza dos processos não representaria mera continuidade, mas uma ruptura em relação à situação anterior.

A autora considera que, no caso da cidade fragmentada, pela fina especialização dos territórios (e não pela generalização empreendida a partir do emprego do conceito de segregação), há proximidade geográfica (e, portanto, uma relativização do processo de distanciamento espacial e que, em grande medida, condiciona uma requalificação das relações entre proximidade e distanciamento socioespacial) entre grupos sociais distintos.

Sobre a requalificação dessas relações, têm-se acentuado os níveis de controle social que interferem na qualidade dos contatos entre os citadinos. Além disso, há uma tendência de mistura dos usos do solo urbano que garantiria um determinado nível de independência com relação à cidade. Segundo Salgueiro (2001, p. 186-187), esses processos tendem a fugir do escopo das análises que dão ênfase, tão somente, ao conceito de segregação.

Com relação à proposição de Salgueiro (2001), nossa discordância se estabelece ante ao fato de que não se trata de substituir um conceito pelo outro, mas sim, analisar, dentro de um contexto contemporâneo, as possibilidades, os limites explicativos e as interações entre os mesmos, levando-se em consideração, o movimento constante de superação (atualização, no tempo e no espaço, e contextualização teórico-conceitual) intrínseco a cada um dos conceitos. 
Ainda ressalvamos que Salgueiro (2001, p. 186) direciona suas críticas a um modelo descontextualizado de segregação socioespacial que se baseou na abordagem da "Ecologia Fatorial", bastante utilizada durante a década de 1960, como ressaltou Villaça (2001, p. 148), utilizando-se de setores censitários, indicadores sociais (para condensar a complexa trama de relações sociais) e técnicas estatísticas para identificar distintos padrões socioespaciais e, como afirmou Sobarzo (1999, p. 34), tendendo a considerá-los como produto final, "sem analisar os fatores e processos" que determinaram a organização desses padrões.

Salgueiro (2001, p. 116) também destaca cinco principais elementos caracterizadores da fragmentação socioespacial na cidade contemporânea:1) Território policêntrico - representativo da perda da hegemonia do centro tradicional a partir da multiplicação de novas centralidades; 2) Áreas mistas - como os megacomplexos imobiliários que combinam moradia, centros comerciais e de serviços que negam o zoneamento funcional da cidade moderna; 3) Enclaves - como os espaços residenciais fechados com grau acentuado de homogeneidade social, implantados de modo contíguo às parcelas dos tecidos urbanos até então, predominantemente, empobrecidos; 4) Dessolidarização do entorno próximo - caracterizados pela formação de redes de relações à distância e do alto nível de acessibilidade, proporcionado a partir do uso intensivo do automóvel e das vias de trânsito rápido, que não valorizam as funções que poderiam ser exercidas nas proximidades imediatas; 5) Valores simbólicos de distinção social, que permitem reafirmar a importância do fragmento a partir de um sistema de identificação - em termos de estilo de vida e padrão de consumo - para os segmentos de mais alto poder aquisitivo.

Um dos recursos que contribuem para a compreensão desses elementos baseia-se na análise das práticas socioespaciais dos sujeitos autossegregados. De acordo com Janoschka e Glasze (2003), a análise dessas práticas deve ser orientada a partir da verificação de um conjunto de atividades diárias, identificando locais utilizados para o trabalho, formação/educação, consumo de bens e de serviços, tempo livre e realização do lazer.

Se a análise identificar uma diminuição de contato entre grupos que se distinguem, no que se refere ao padrão socioeconômico e estilo de vida, como consequência da mudança para espaços residenciais fechados, poderia caracterizar-se como fragmentação, mesmo que não abarque todas essas atividades diárias citadas (JANOSCHKA e GLASZE, 2003, p. 16-17).

Janoschka e Glasze (2003, p. 16) destacam que, a partir das associações constituídas dos espaços residenciais fechados, outra dimensão da fragmentação também comparece quando um conjunto de regras, inclusive arquitetônicas e urbanísticas, regulam a convivência e características internas desses espaços. Do ponto de vista político-territorial, firmam-se, portanto, como áreas mais ou menos autônomas frente ao poder público municipal.

Como reforço à diminuição de contato entre as diferenças, o processo de fragmentação socioespacial tende a estabelecer um efetivo afastamento com determinadas parcelas do espaço urbano, sobretudo, àquelas caracterizadas por uma segregação imposta.

Essa dimensão da fragmentação socioespacial contribui para promover, junto aos sujeitos de médio a alto poder aquisitivo que optam pela autossegregação, um relativo desconhecimento e desvalorização da cidade enquanto um bem coletivamente compartilhado.

\section{FRAGMENTAÇÃO SOCIOESPACIAL EM ESPAÇOS URBANOS DE DIFERENTES PORTES}

Ao analisar os enclaves fortificados, Caldeira (2000, p. 273) ressalta que os empreendimentos Aldeia da Serra, Alphaville e Tamboré, localizados na Região Metropolitana de São Paulo, visaram combinar espaços residenciais fechados, shopping centers e conjuntos de escritórios, de modo mais ou menos semelhantes ao modelo dos subúrbios estadunidenses.

O complexo de Alphaville foi implantado no Município de Barueri e se estendeu até envolver parte do Município de Santana do Parnaíba. Este complexo possui 13 “condomínios horizontais", com tendência de verticalização em alguns pontos. No complexo também foram implantados o 
"Centro Comercial de Alphaville", o "Alphashopping", cinquenta escritórios imobiliários, duas clínicas médicas, seis escolas e uma universidade. Além disso, no complexo também se encontram o "Alphaville Tênis Clube" e o "Cine-Teatro Alphaville" ambos destinados ao lazer e ao entretenimento (SOUZA, 2000, p. 199-201).

Contíguos ao Alphaville estão localizados espaços residenciais em terrenos acidentados, ocupados pelos segmentos sociais de menor poder aquisitivo, produzindo uma paisagem urbana bem representativa de contrastes (SEABRA, 2004, p. 198).

Janoschka (2003) faz referência à Nordelta, megaempreendimento localizado a uma distância de trinta quilômetros ao norte de Buenos Aires, com cerca de vinte espaços residenciais fechados associados às grandes equipamentos comerciais e de serviços (incluso centros médicos e universidades). Segundo o autor, o empreendimento foi projetado para estar separado do "resto da vida urbana" a partir do emprego de sistemas de segurança privada.

No que se refere ao consumo de bens e de serviços, com o estímulo à circunscrição das práticas socioespaciais no âmbito deste megaempreendimento, os moradores de Nordelta tenderam a reduzir as saídas para o Centro de Buenos Aires. Além disso, Janoschka (2003) também ressalta que vem ocorrendo um maior consumo de meios modernos de comunicação (telefone móvel celular e Internet) que permitiram evitar determinados deslocamentos.

Em Mendoza (metrópole localizada na porção oeste da Argentina), durante as últimas décadas vários espaços residenciais fechados foram implantados no Setor Sul e próximos as principais vias de circulação. Alguns desses empreendimentos foram implantados justapostos a centros comerciais e de serviços demonstrando uma clara tendência de "fragmentação socioeconômica do espaço", na qual, também se traduz pelo processo de afastamento para com os bairros mais pobres localizados nas proximidades (SCHMIDT, 2003, p.13).

Ao verificar os processos de produção da cidade de Guadalajara, no México, Aceves et al (2004, p. 292) apontam que vêm ocorrendo o debilitamento das dimensões de interação e alteridade da cidade a partir das ações de determinados grupos, que optam pela desconexão com o mundo exterior, gerando a perda dos interesses comuns e a fragmentação da consciência cidadã, anulando a responsabilidade para com o conjunto da cidade.

Andrade (2005, p. 845; 2006, p. 305-309) faz referência ao Alphaville Lagoa dos Ingleses, lançado em 1998, e ao Vale dos Cristais, lançado em 2004, ambos localizados no Município de Nova Lima, na Região Metropolitana de Belo Horizonte. Os dois empreendimentos visam reunir espaços residenciais fechados, associados a centros empresariais e centros comerciais e de serviços, gerando uma ideia, amplamente divulgada pelos empreendedores imobiliários, que está se constituindo uma "nova cidade".

Essa mesma lógica permite estabelecer "barreiras" para os segmentos de menor poder aquisitivo, considerando que os sujeitos que pertencem a esses segmentos, em geral, dispõem de menos recursos para se locomoverem por automóvel particular e, portanto, possuem um maior grau de dificuldade para percorrer a autopista e obter acesso aos mesmos equipamentos de consumo. A produção dessas novas centralidades urbanas reforça o sentimento de pertencimento e de distinção dos segmentos de mais alto poder aquisitivo ao mesmo tempo em que promovem o afastamento dos segmentos mais pobres (ARIZAGA, 2004, p.50-52).

Dattwyler et al (2005, p. 6917) fazem referência à "Pedra Roja", lançado em 2003, localizado na cidade de Chicureo, ao norte da capital chilena. Projetado para ser uma "cidade cercada", este megaempreendimento possui doze mil lotes residenciais, dez escolas, duas universidades, nove centros esportivos, duas clínicas médicas, dezessete centros comerciais, cinco templos religiosos e uma laguna navegável.

Ao sul de "Pedra Roja", localizam-se mais duas "cidades cercadas" denominadas "Vale Norte" e "La Reserva". Em geral, os espaços residenciais fechados (excetuando as "cidades cercadas") e grandes equipamentos comerciais e de serviços concentram-se ao longo das vias de acesso rápido na porção leste de Santiago (DATTWYLER et al, 2007). 
Ainda que os empreendimentos imobiliários localizados em algumas metrópoles caracterizem-se como exemplos de um alto nível de fragmentação socioespacial, também há indícios para o aparecimento e, até mesmo, para o estabelecimento de um nível intermediário de fragmentação, em cidades de porte médio latino-americanas.

A partir das observações de Schmidt (2003, p. 1), podemos considerar que, embora a fragmentação socioespacial em curso em algumas cidades de porte médio tenha similaridade com o processo que vêm ocorrendo em espaços urbanos metropolitanos, o processo se diferencia por grau de intensidade e se caracteriza a partir de ritmos próprios.

Ao analisar a produção de espaços residenciais fechados em cidades médias paulistas, Sposito (2006, p. 186) ressalta que as descontinuidades do tecido urbano se realizam, sem que os maiores custos econômicos e os tempos de deslocamentos se transformem num entrave frente aos interesses fundiários e imobiliários, dos agentes que viabilizam esse tipo de habitat urbano, em áreas periféricas e descontínuas ao tecido urbano compacto.

Além disso, a produção de novas centralidades impulsionadas pelo uso do automóvel e pelo aumento do tempo destinado ao consumo promoveu alterações "no papel e na estrutura do centro principal" provocando "uma redefinição do centro, da periferia e da relação centro-periferia" (SPOSITO, 1996a, p. 114) ocasionando rupturas com as estruturas monocêntricas que predominaram nessas cidades até a década de 1970 (SPOSITO, 2007).

No que se refere à produção de novas centralidades, há uma tendência de associação entre a implantação de espaços residenciais fechados e as novas escolhas locacionais de atividades comerciais e de serviços (SPOSITO, 2007).

Também devemos considerar a hipótese de que a aglomeração de espaços residenciais fechados joga um peso decisivo, mas não exclusivo, diante do processo de formação de novas centralidades, incluindo a qualidade dos equipamentos públicos e infraestruturas existentes. Em geral, a concentração dos segmentos de alto poder aquisitivo, incluindo os moradores de espaços residenciais fechados, contribuem para o processo (BOTELHO, 2007, p. 35).

Ao analisar o processo de produção de espaços residenciais fechados em São José do Rio Preto - SP, Sposito (2003), faz referência ao "Green Valley Edge City", empreendimento imobiliário subdividido em três espaços residenciais fechados, cujo projeto contempla, em contiguidade a esses habitats urbanos, a construção de um centro comercial.

A partir da análise dos discursos anunciados pelos incorporadores que implantaram este empreendimento, a autora ressalta que as práticas socioespaciais ensejadas estão apoiadas no desejo de se estabelecer um alto grau de ligação/fluidez espacial, associando-se a um baixo grau de interação social e de laços de compartilhamento territorial com a cidade.

Os discursos que promovem a segmentação enfatizam as vantagens do Setor Sul (área de maior concentração de espaços residenciais fechados em São José do Rio Preto) na qual, pela oferta de equipamentos comerciais e de serviços, possibilitam aos moradores circunscrever a maior parte de suas práticas socioespaciais neste setor (SPOSITO, 2003a).

Em Sorocaba - SP, há uma tendência de concentração de espaços residenciais fechados no Setor Leste, próximos à Rodovia Raposo Tavares, permitindo rápido acesso ao principal shopping center da cidade (SPOSITO, 2007).

Em Presidente Prudente - SP, os loteamentos fechados tendem a se concentrar no Setor Sul e cujos moradores tendem a estabelecer um alto nível de acessibilidade aos dois shopping centers da cidade. Boa parte das saídas voltadas ao consumo, também se realizam ao longo das principais vias que dão acesso a esses loteamentos (DAL POZZO, 2009).

Em síntese, essas pesquisas demonstram que, nas cidades de porte médio, há uma tendência de que o processo de segmentação socioespacial passa a operar não apenas no âmbito do consumo de determinado tipo de habitat urbano, mas também, no âmbito do consumo na cidade o que, em grande medida, contribui com o processo de fragmentação socioespacial e tende a interferir 
na qualidade (e nos níveis de intensidade) da sociabilidade entre os citadinos que se distinguem socioeconomicamente.

Além de uma diminuição de contato entre as diferenças, o processo de fragmentação socioespacial também tende a estabelecer um efetivo afastamento com determinadas porções do espaço urbano, sobretudo, àquelas caracterizadas por uma segregação imposta.

Esse afastamento socioespacial se relaciona com questões envolvendo descontinuidades e contiguidades territoriais, nas quais, são reforçadas por meio de mecanismos de controle social, em detrimento da continuidade territorial da cidade.

De um modo geral, com a expressiva tendência de expansão dos espaços urbanos de porte médio a padrões metropolitanos durante as três últimas décadas, a continuidade territorial que caracterizou esses espaços passa por processos de ruptura advindos de práticas que valorizam as intencionalidades das descontinuidades e contiguidades territoriais.

As descontinuidades e as contiguidades territoriais - em especial, àquelas contiguidades que são designativas do desejo pelo consumo segmentado da cidade (grandes equipamentos urbanos, privados e de consumo coletivo, como os clubes, shopping centers, hipermercados, bem como, os espaços residenciais fechados) - contribuem com o estabelecimento de um efetivo controle social discursivamente justificado como meio de assegurar "qualidade de vida", baixos níveis de sensação de insegurança urbana e o direito de não ser incomodado em ambientes cujas ações e reações são, em geral, muito previsíveis.

Com isso, o controle social que se realiza no âmbito da fragmentação socioespacial, tende a não ser traduzido em termos de confronto entre as diferenças (ainda que possa haver tensões entre elas), mas sim, num tipo de oposição que tende a ser expresso por meio de um conjunto de esforços individuais, familiares e empresariais que, dispondo de poder socioeconômico e do desejo de optar pelo afastamento socioespacial com determinadas parcelas da cidade, condicionam um maior grau de neutralização de determinados tipos de ações e de comportamentos que possam comprometer a lógica do consumo e a primazia da valorização econômica das porções de áreas caracterizadas pela fragmentação.

\section{FRAGMENTAÇÃO SOCIOESPACIAL EM MARÍLIA E SÃO CARLOS}

Os Municípios de Marília e São Carlos estão a uma distância rodoviária de $276 \mathrm{Km}$ entre si. Marília, localizado a Oeste do Estado de São Paulo, está a uma distância de $426 \mathrm{Km}$ da capital. Por sua vez, São Carlos, localizado na porção mais central do Estado de São Paulo, está a uma menor distância da capital paulista, qual seja, de $237 \mathrm{Km}$ (CAMARGO, 2008, p. 71). A localização desses dois Municípios, no Estado de São Paulo, bem como, as principais rodovias que os ligam entre si e a São Paulo, podem ser observadas na figura 1.

O estudo da fragmentação socioespacial nestas duas cidades justificou-se, sobretudo, pela expressiva presença nelas de espaços residenciais fechados, pela localização desses empreendimentos e pela disponibilidade de vias de acesso rápido a eles, possibilitando aos seus respectivos moradores, estabelecer níveis elevados de acessibilidade aos grandes equipamentos urbanos destinados ao consumo, presentes em ambas.

Além disso, podemos considerar que, embora Marília e São Carlos tenham portes demográficos e ritmos de crescimento urbano semelhantes nos últimos vinte anos, essas cidades distinguem-se, sobretudo, se considerarmos os papéis que desempenham na rede urbana paulista (SPOSITO, GOES e SOBARZO, 2006).

Marília vem se destacando pela ampliação relativa na participação do PIB industrial paulista, enquanto São Carlos vem se notabilizando como polo tecnológico a partir da implantação de centros de pesquisa nesse Município (SPOSITO, GOES e SOBARZO, 2006). 


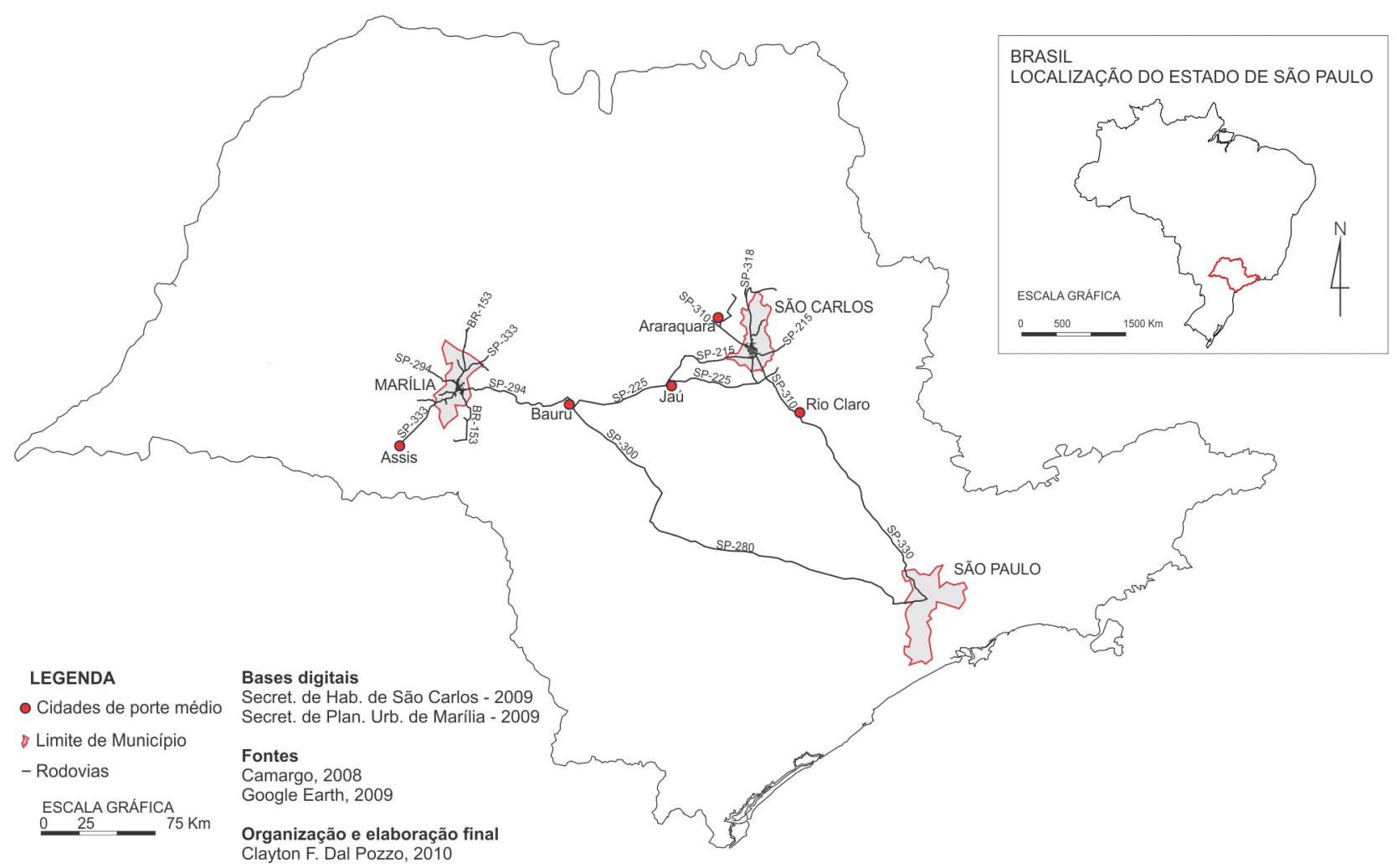

Figura 1 - Estado de São Paulo

Localização dos Municípios de São Paulo, de Marília e de São Carlos

A expansão territorial dessas cidades também se distingue notando-se descontinuidades territoriais em ambas, porém, São Carlos conforma uma aglomeração urbana com a cidade de Araraquara enquanto Marília, decorrente das características geomorfológicas de seu espaço urbano , possui uma estruturação mononuclear e com limitações para uma efetiva dispersão urbana (SPOSITO, GOES e SOBARZO, 2006).

Considerando essas semelhanças e diferenças, analisamos dinâmicas e especificidades desses tecidos urbanos a partir do emprego de procedimentos metodológicos que visaram levantar dados e informações pertinentes ao tema problematizado.

Foram encaminhados questionários aos sujeitos autossegregados nestas duas cidades. Muito embora os resultados obtidos não se caracterizem como uma amostragem estatisticamente representativa, os conteúdos das respostas nos orientaram em análises comparativas considerando tendências de espacialização das práticas socioespaciais deles.

Os depoimentos dos sujeitos autossegregados também foram registrados, a partir da realização de entrevistas estruturadas, acumulando-se informações representativas das preferências pelo uso de locais específicos, para a realização de atividades cotidianas, incluso, as opções (e motivações) para não se frequentar determinadas porções do espaço urbano.

Como pode ser analisado a partir da figura 2, os espaços residenciais fechados implantados em Marília tendem a estar localizados no setor instituído pela municipalidade como "Zona Leste". Nesta Zona (a qual, em nossa pesquisa, foi subdividida em dois quadrantes), há um grande destaque para a formação de novas centralidades urbanas (fomentadas pela presença de hipermercados, estabelecimentos comerciais e de serviços exclusivos e o Esmeralda Shopping) em duas de suas principais vias de acesso. 


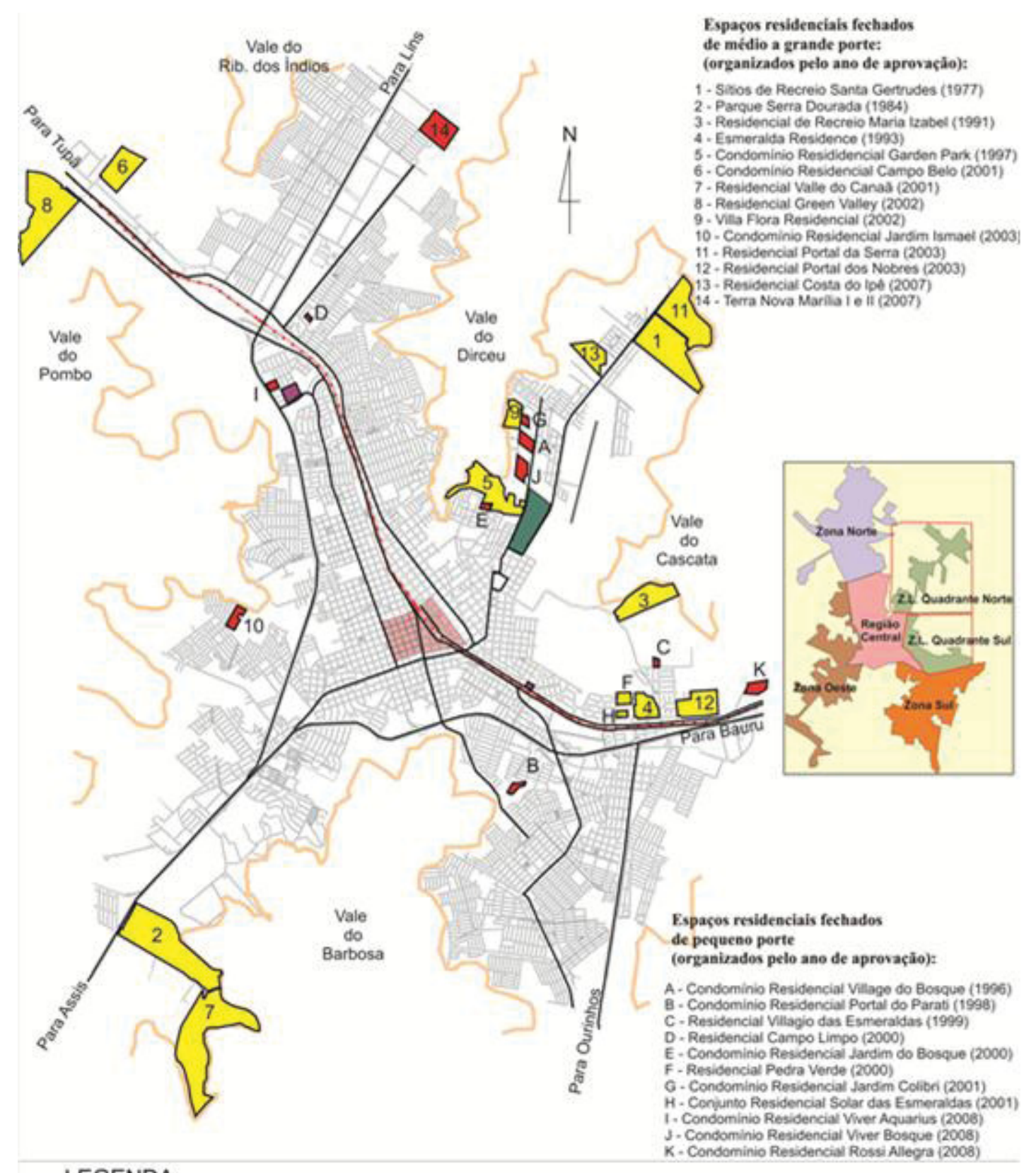

\section{LEGENDA}

ERFs voltados aos segmentos de alto poder aquisitivo

ERFs voltados aos segmentos de médio poder aquisitivo

Bosque Municipal

Centro

Shopping Center
Base digital: Secretaria de Planej, Urbano de Marilia - 2009
Fonte: Zandonadi, 2008; Pesquisa de campo, 2010
Organizaçào e elaboraça final.: Clayton F. Dal Pozzo, 2010

Figura 2 - Marília

Localização dos espaços residenciais fechados

Já em São Carlos, como pode ser analisado a partir da figura 3, os espaços residenciais fechados tendem a se localizar próximos e ao longo das principais vias intraurbanas de circulação rápida, 
sobretudo, no Setor Norte e no Setor Noroeste (com destaque para o Parque Faber I, Parque Faber II e Residencial Swiss Park, empreendimentos residenciais fechados, situados em contiguidade com o Shopping Iguatemi).

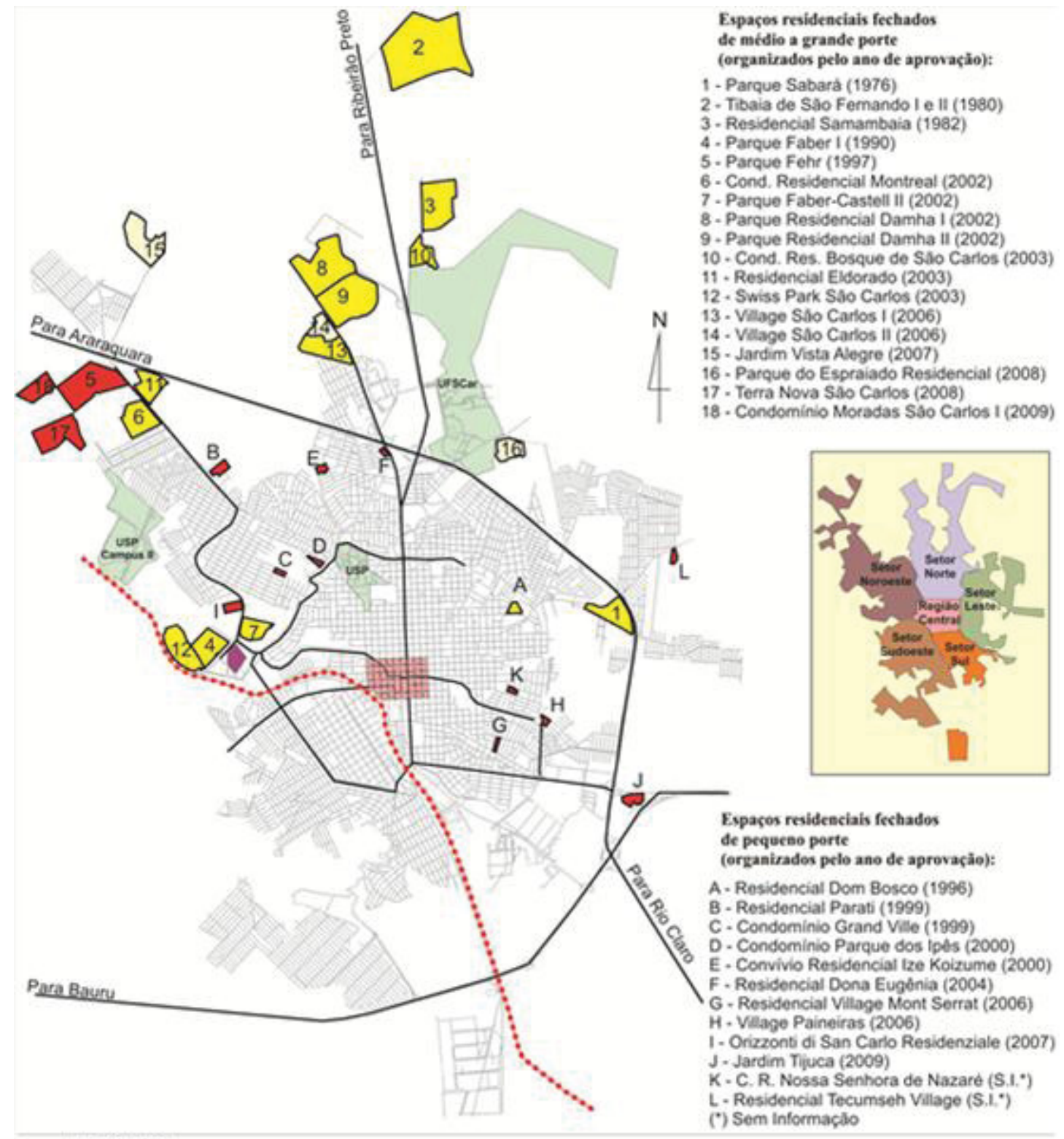

\section{LEGENDA}

ERFs voltados aos segmentos sociais de alto poder aquisitivo

ERFs voltados aos segmentos sociais de médio poder aquisitivo

Campi Universitários

ERFs não classificados

Centro

- Principais vias

Shopping Center

.... Via férrea

Base digital: Secretaria de Habitaçâo - 2009

Fonte: Lante, 2007: Pesquisa de campo, 2010

Org. e elaboraça finat. Clayton F. Dal Pozzo, 2010

Figura 3 - São Carlos

Localização dos espaços residenciais fechados

Nestas duas cidades, até meados da década de 1970 intensificou-se a diferenciação socioespacial que tendeu a orientar a ocupação dos setores urbanos, segundo níveis socioeconômicos distintos. Em função disto, enquanto a Zona Leste de Marília e o Setor Noroeste de São Carlos tenderam a ser ocupados pelos segmentos de médio a alto poder aquisitivo, por outro lado, as Zonas Sul e 
Norte de Marília e o Setor Sudoeste de São Carlos, foram ocupados, predominantemente, pelos segmentos sociais de mais baixo poder aquisitivo.

Na década de 1980 a produção do espaço urbano deixa de ser orientado somente pelo processo de diferenciação socioespacial e passa também a se redefinir, segundo processos de segregação socioespacial. Neste período, houve uma acentuada expansão que se caracterizou pelo processo de ruptura com a continuidade territorial da cidade. Além da presença dos grandes vazios urbanos, alguns objetos técnicos (ferrovias e rodovias) e naturais (as escarpas em Marília e a Encosta Sul em São Carlos) também contribuem com esse processo.

As disparidades socioeconômicas também se intensificam com os processos de favelização. Em São Carlos, esse processo tendeu a aparecer no Setor Sudoeste e, em Marília, de modo mais acentuado e disperso, ocorreram nas Zonas Sul, Oeste e Norte.

Na década de 1990 e, sobretudo, após o ano de 2000, intensificou-se a ocupação de espaços residenciais fechados, propiciando um maior afastamento entre os segmentos de mais baixo poder aquisitivo (os quais têm pouco poder de decisão de onde e como morar e, portanto, tendem a serem condicionados por um processo de segregação imposta) e os segmentos de mais alto poder aquisitivo (os quais têm o poder de justificar e, de fato, optar pela autossegregação).

Assim, a segregação socioespacial torna-se mais complexa porque segundo essa estruturação, não se trata apenas de firmar uma segmentação residencial, mas, de considerar o modo como esses sujeitos realizam as práticas socioespaciais considerando a cidade.

Para os sujeitos autossegregados, a opção pelo afastamento ante aos segmentos de menor poder aquisitivo, na medida em que houve a escolha pela "neutralização" das diferenças, esboça-se um determinado território que também se delimita por um processo de integração seletiva e tendencialmente segmentada do espaço urbano.

Os territórios de autossegregação também se realizam no processo de oposição aos territórios de segregação imposta, tendo em vista que a possibilidade do confronto e compartilhamento de significados entre aqueles que os compõem. (e que tendem a se distinguir, sobretudo, no âmbito da dimensão socioeconômica), se atenua.

Para melhorar analisar esses processos, elaboramos as figuras 4 e 5, tendo em vista, representar a espacialização das práticas socioespaciais dos sujeitos autossegregados, respondentes de nosso questionário.

No processo de elaboração das figuras 4 e 5, houve a necessidade de estabelecer agrupamentos de espaços residenciais fechados combinando proximidade espacial e nível de poder aquisitivo em potencial deles. Este procedimento possibilitou indicar tendências de realização das práticas socioespaciais segundo esses mesmos critérios de agrupamento.

Também delimitamos algumas áreas, as quais são representativas dos territórios de autossegregação e de segregação imposta. Além disso, são nos territórios de autossegregação que os segmentos de médio e, sobretudo, os de alto poder aquisitivo, que moram nos espaços residenciais fechados pesquisados, tendem a circunscrever suas práticas socioespaciais.

Em geral, os territórios de autossegregação contemplam dotações infraestruturais (sobretudo, no que se refere às vias de acesso rápido), e em função da presença de grandes equipamentos urbanos (e que, por vezes, também ofertam grandes áreas de estacionamentos), são voltados para o consumo de bens e de serviços, incluso, o lazer.

A identificação dos territórios de segregação imposta relaciona-se com as indicações espaciais dos sujeitos autossegregados relativas às áreas, do espaço urbano, mais preteridas (ante a possibilidade de uma nova moradia) e que não são frequentadas ou não se tem contato.

Contudo, para uma análise mais criteriosa dos territórios de segregação imposta, as práticas socioespaciais dos sujeitos segregados, também deveriam ser analisadas, o que não foi contemplado por nossa pesquisa. Ressaltamos, portanto, a necessidade de novas pesquisas que possam avaliar 


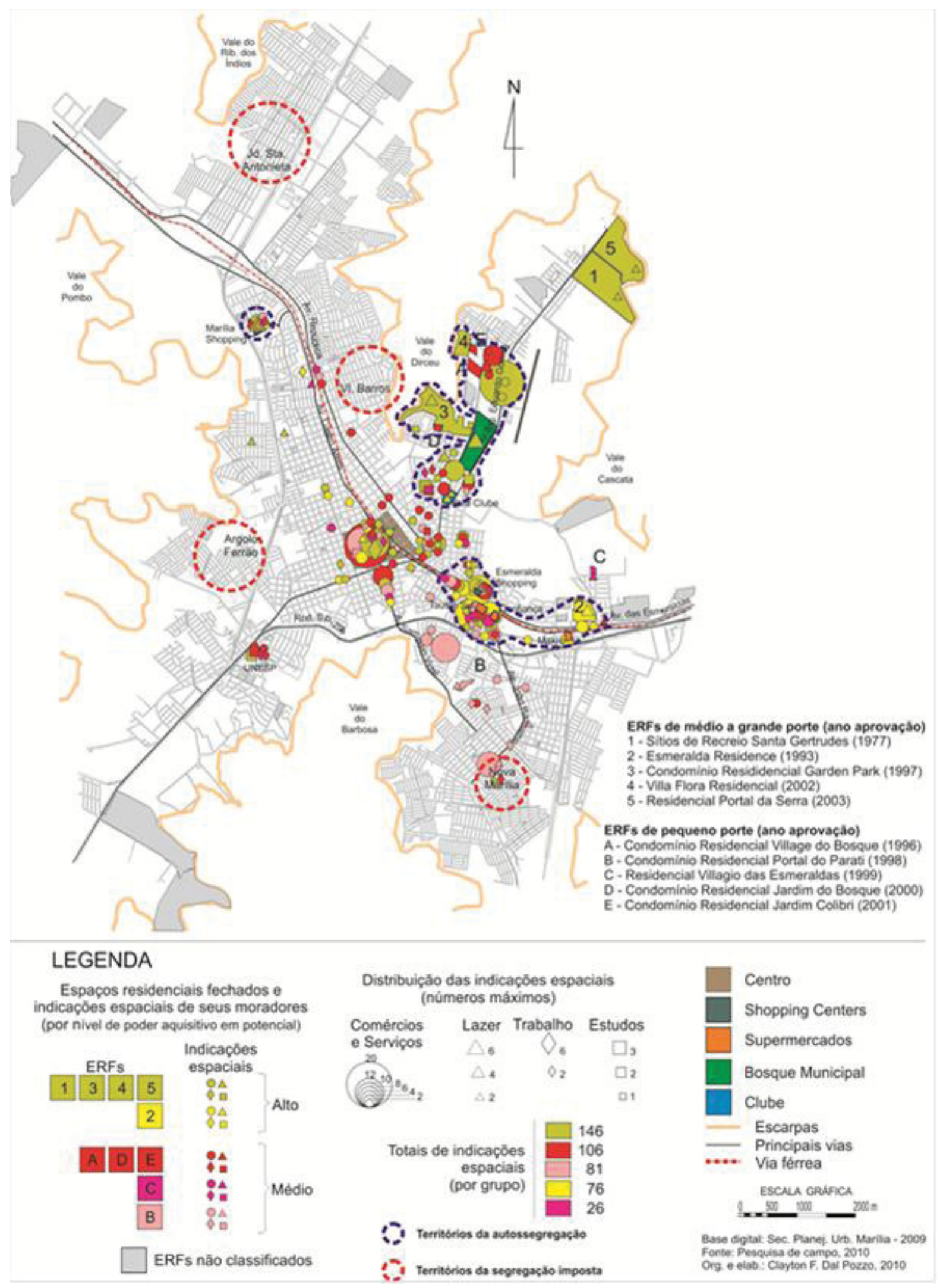

Figura 4 - Marília

Territórios de autossegregação e da segregação imposta 


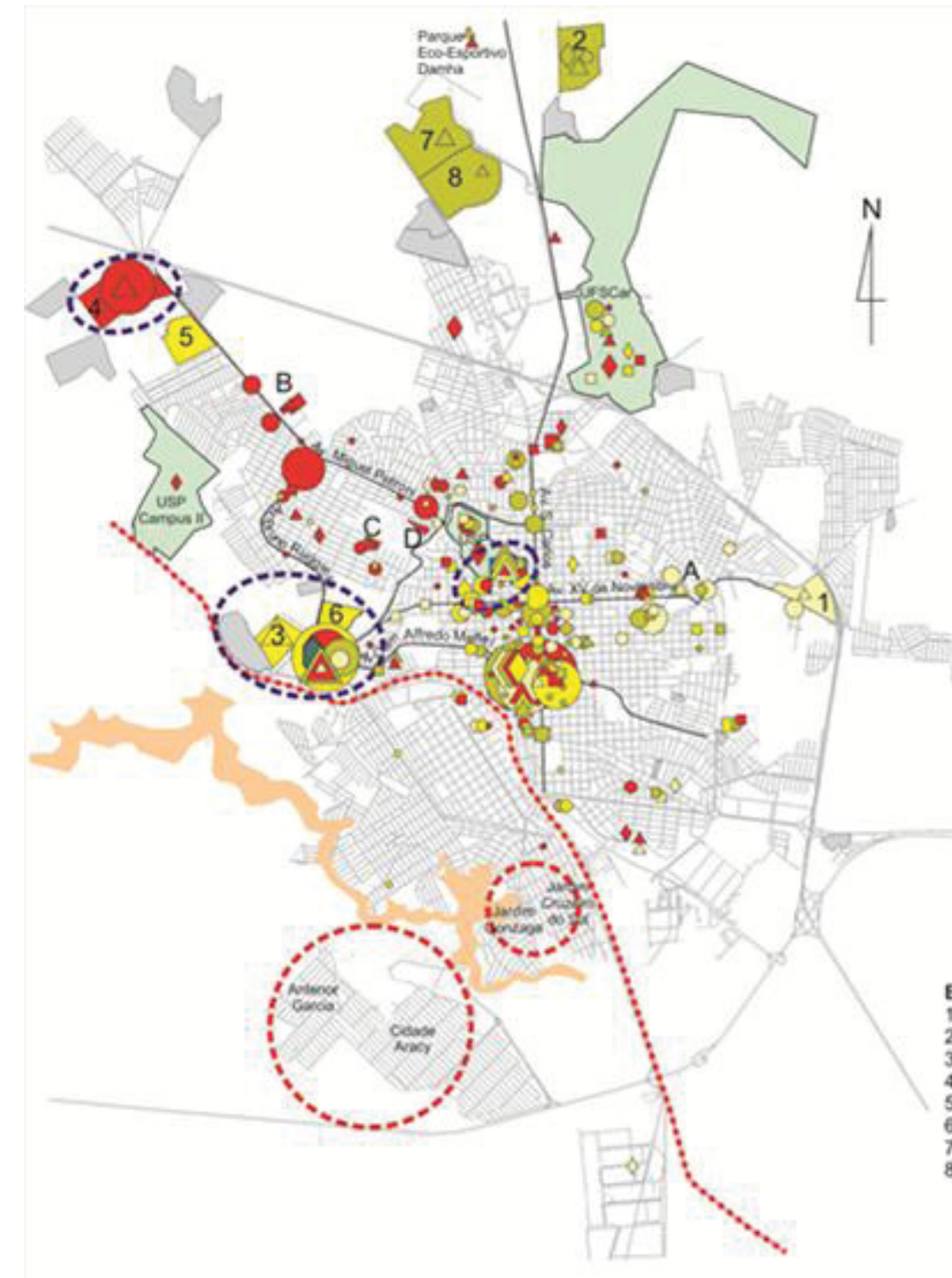

ERFs de medio a grande porte (ano aprovaçà) 1.- Parque Sabard (1976)

3. Parque Faber I (1990)

4. Parque Fehr (1997)

5. Cond. Residencial Montreal (2002)

6 - Parque Faber-Castell II (2002)

7. Parque Residencial Damha I (2002)

8 - Parque Residencial Damha II (2002)

ERFs de pequeno porte (ano aprovaçäo) A - Residencial Dom Bosco (1996)

B - Residencial Parati (1999)

C. Condomínio Grand Ville (1999)

D. Condominio Parque dos lpts (2000)

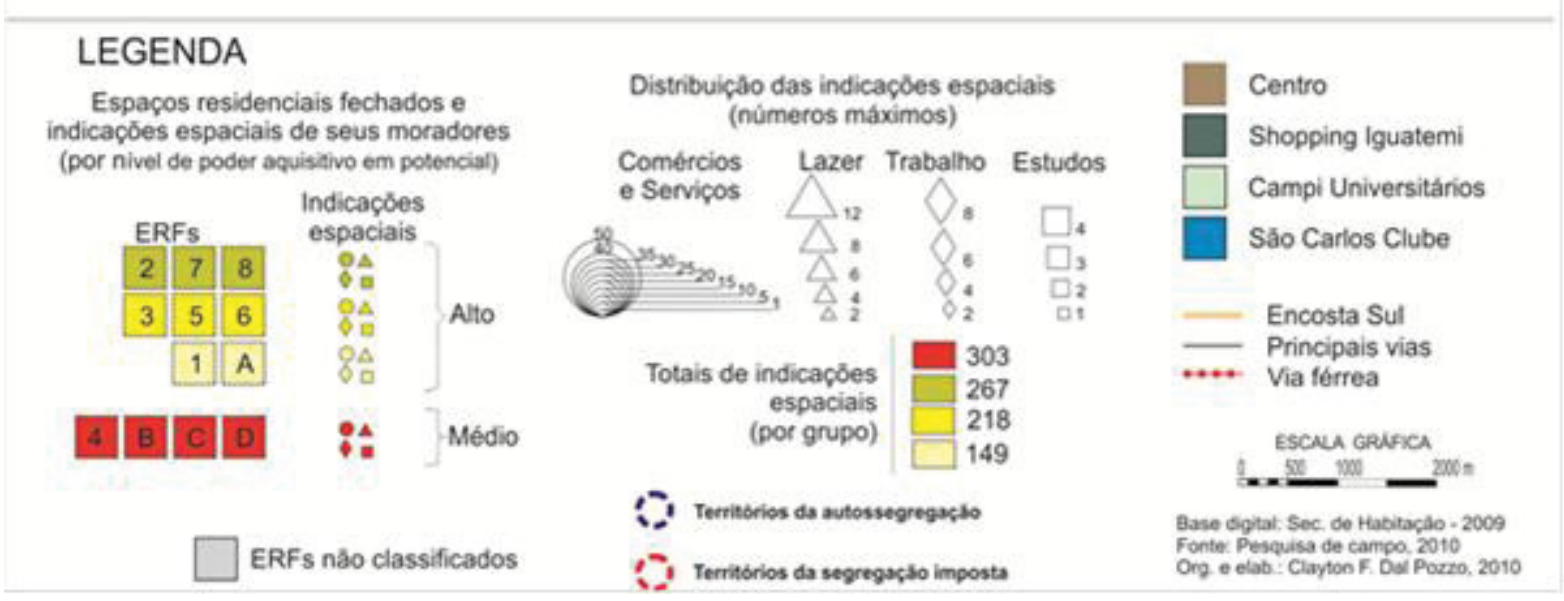

Figura 5 - São Carlos

Territórios de autossegregação e da segregação imposta 
como se realizam o uso e o consumo do espaço urbano, na perspectiva de uma comparação analítica equânime entre os sujeitos segregados e autossegregados.

Em geral, as características que possibilitaram definir a fragmentação socioespacial em Marília e São Carlos remetem às tendências de uma integração espacial limitada e circunscrita, alterações na preponderância do consumo do centro em favor de novas centralidades (e, portanto, dos territórios de autossegregação) e um grau acentuado de oposição/neutralização com determinadas parcelas do espaço urbano, representativas de uma segregação imposta.

Além disso, a tendência à aglomeração de espaços residenciais fechados em algumas porções do espaço urbano e a circunscrição das práticas socioespaciais dos sujeitos autossegregados associadas ao aparecimento de novas centralidades urbanas, contribuem para acentuar o processo de consumo segmentado na cidade.

Os moradores de espaços residenciais fechados voltados aos segmentos de médio poder aquisitivo, embora contribuam para a formação dos territórios de autossegregação, o peso de suas participações é menor, sobretudo, porque o conjunto de suas práticas socioespaciais tende a se realizar de modo mais disperso e integrado ao conjunto da cidade.

Já os moradores de espaços residenciais fechados, voltados aos segmentos de alto poder aquisitivo, são os que mais contribuem para a formação desses territórios, pois, suas práticas socioespaciais expressam níveis de integração espacial menor e mais circunscrito.

Em Marília, os territórios de autossegregação tendem a competir e, até mesmo, retirar a preponderância do centro em favor das novas centralidades. Já o Centro de São Carlos se caracteriza como local preferido para a realização do conjunto das práticas socioespaciais dos sujeitos autossegregados. Assim, os territórios de autossegregação em Marília tendem a ser mais expressivos (ante a articulação menos acentuada com o centro) do que em São Carlos.

As práticas socioespaciais ensejadas pelos sujeitos autossegregados em São Carlos também denotam uma maior integração espacial com a cidade do que aquela ensejada em Marília. Em Marília, as práticas socioespaciais dos sujeitos autossegregados tendem a se realizar, de modo mais expressivo, apenas na Zona Leste e, em menor medida, no Centro. Já em São Carlos, elas se realizam considerando uma área urbana mais extensiva.

No processo de definição dos níveis de fragmentação socioespacial em cidades de porte médio também comparece o grau de oposição entre os territórios de autossegregação e de segregação imposta. Em São Carlos, muito embora, haja uma grande oposição em relação ao Setor Sudoeste e, em especial, aos territórios de segregação imposta que aí se localizam, o mesmo não ocorre de modo igualmente intenso, com os demais setores do espaço urbano.

Em Marília, considerando as características de seu sítio urbano, houve mais elementos para reforçar as descontinuidades territoriais. Além disso, nesta cidade, houve um número maior de casos representativos de processos de favelização e que tenderam a se localizar em áreas próximas às escarpas, sobretudo nas Zonas Sul, Norte e Oeste, como já ressaltado.

O processo de oposição/neutralização entre os territórios de autossegregação e de segregação imposta se realiza, com exceção do Centro, nestas respectivas Zonas opondo-se, portanto, a uma área urbana mais extensa do que a oposição que se realiza em São Carlos.

Com base nesse conjunto de aspectos, o nível de fragmentação socioespacial que tende a se esboçar no espaço urbano de Marília tende a ser mais acentuado do que a fragmentação que se realiza em São Carlos.

\section{CONSIDERAÇÕES FINAIS}

A partir da análise dos processos de fragmentação socioespacial em Marília e São Carlos podemos considerar que, no âmbito político, o reconhecimento das desigualdades sociais, bem como, as possibilidades de superação delas, tendeu a não estar presente nos discursos dos sujeitos autossegregados. 
De modo menos expressivo ainda, não foi possível vislumbrar aberturas de um projeto coletivo da cidade que estivesse pautado politicamente na equidade socioespacial, pelo contrário, o fomento aos processos de fragmentação socioespacial representam uma força contra a própria ideia de cidade.

Esse aspecto da fragmentação socioespacial se traduz a partir de um menor nível de compartilhamento de significados e de territórios entre os citadinos e, sobretudo, entre o morador da cidade aberta (em especial, os citadinos mais pobres) e o morador autossegregado (em geral, pertencentes aos segmentos de médio a alto poder aquisitivo).

Com base nisso, sugerimos uma avaliação crítica à preponderância de uma das principais justificativas que levam parte dos citadinos a optar pela autossegregação: a (sensação de) insegurança urbana, uma vez que esse tipo de necessidade remete à adoção de mecanismos de controle social que assegurem, de fato, um elevado grau de neutralização dos incômodos e que também se associam a maior afastamento entre as diferenças.

Reforçando esse aspecto, os respondentes e entrevistados, moradores de espaços residenciais fechados tenderam a expressar uma miríade de outras justificativas. Entre elas, aquela que nos chamou mais atenção, foi o direito de não ser incomodado num ambiente cujos comportamentos e ações são, em geral, normatizados e previsíveis.

Esta dimensão da fragmentação socioespacial também enseja que esse processo possa ser estendido a outros espaços privados, tendo em vista, valorizar a dimensão de um consumo segmentado, como escolas privadas de ensino básico, clubes e shopping centers.

No que tange à dimensão espacial, a fragmentação socioespacial, necessariamente, não impede o estabelecimento de relações entre sujeitos autossegregados e aqueles submetidos a uma segregação imposta. Porém, o tipo de contato/relação realizado, em geral, no âmbito profissional, tende a propiciar pouca abertura para o compartilhamento de experiências e significados entre os diferentes, o que denota uma baixa expectativa quanto à possibilidade de uma cidade mais equitativa. No âmbito político, portanto, o compartilhamento espacial entre as diferenças nem sempre são pressupostos de justiça espacial.

Considerando outro aspecto, o projeto coletivo de um espaço condominial que, salvo exceções, caracteriza a proposta dos espaços residenciais fechados contemplados por nossa pesquisa, tende a ser desmistificado na medida em que a fragmentação socioespacial, do ponto de vista das tensões e fragilidades das relações sociais, em geral, também tende a se estender aos "idênticos" que compartilham o mesmo habitat urbano.

É nesse sentido que também ressaltamos a importância de realização de novas pesquisas que possam melhor avaliar a qualidade e os níveis de intensidade de uma sociabilidade segmentada (permeada por processos que reforçam o isolamento e individualismos) e a expressão desta em termos de projetos comuns a um determinado grupo e a expressão destes, considerando a cidade.

Esses tensionamentos, promovidos por processos de fragmentação socioespacial, sugere a desvalorização da alteridade, a tendência do não encontro, da não relação e do processo de negação das diferenças.

A fragmentação socioespacial, portanto, tende a agir contra a utópica concepção de vida urbana de Lefebvre (1991, p. 15), na qual pressuporia "encontros, confrontos das diferenças, conhecimentos e reconhecimentos recíprocos (inclusive no confronto ideológico e político), dos modos de viver, dos "padrões" que coexistem na Cidade".

\section{REFERÊNCIA BIBLIOGRÁFICA}

ACEVES, Jorge; TORRE, Renée; SAFA, Patrícia. Fragmentos urbanos de una misma ciudad. Espiral. Guadalajara (México): Universidad de Guadalajara, n. 031, v. 11. p. 277-320, set-dez, 2004.

ANDRADE, Luciana Teixeira. Os condomínios fechados e as novas dinâmicas metropolitanas. In: Anais do X Encontro de Geógrafos da América Latina, São Paulo: USP, 2005, p. 837-852, 1 CD-ROM. 
ARIZAGA, Maria Cecilia. Espacialización, estilos de vida y clases medias: procesos de suburbanización en la Región Metropolitana de Buenos Aires. Perfiles Latinoamericanos. Distrito Federal (México): Facultad Latinoamericana de Ciencias Sociales, n. 025, p. 43-58, dez. 2004

BOTELHO, Adriano. O urbano em fragmentos: a produção do espaço e da moradia pelas práticas do setor imobiliário. São Paulo: Annablume, 2007.

CALDEIRA, Teresa Pires do Rio. Cidade de muros: crime, segregação e cidadania em São Paulo. São Paulo: Ed. 34/Edusp, 2000.

CAMARGO, José Eduardo. Guia Rodoviário 2008. São Paulo: Ed. Abril, 2008.

CORRÊA, Roberto Lobato. O espaço urbano. $4^{\mathrm{a}}$ ed. São Paulo: Ática, 2005.

DAL POZZO, Clayton Ferreira. Fragmentação socioespacial em Presidente Prudente - SP: autossegregação e práticas socioespaciais em questão In: Encontro Nacional da ANPEGE: Espaço e tempo: complexidade e desafios do pensar e do fazer geográfico, 8., 2009, Curitiba. Anais do VIII ENANPEGE. Ponta Grossa: ANPEGE, 2009. 1 CD-ROM.

DATTWYLER, Rodrigo Hidalgo; BORSDORF, Axel; SÁNCHEZ, Rafael. Globalización, neoliberalismo y producción inmobiliaria: hacia la ciudad vallada en las capitales del cono sur. El caso de Santiago de Chile. In: Anais do X Encontro de Geógrafos da América Latina, São Paulo: USP, 2005, p. 6904-6925, 1 CD-ROM. DATTWYLER, Rodrigo Hidalgo; BORSDORF, Axel; SÁNCHEZ, Rafael. La expansión residencial amurallada en la reconfiguración metropolitana en Santiago de Chile. In: Taller Nacional sobre Migración interna y desarrollo en Chile: "diagnóstico, perspectivas y políticas". Santiago (Chile): CELADE-División de Población, 2007 Disponível em: <http://www.eclac.org/celade/noticias/paginas/5/28295/RHidalgo.pdf>. Acesso em: 11 dez. 10.

JANOSCHKA, Michael. Nordelta - Ciudad cerrada. El análisis de un nuevo estilo de vida en el Gran Buenos Aires. Scripta Nova. Revista electrónica de geografía y ciencias sociales. Barcelona: Universidad de Barcelona, n. 146(121), vol. 7, 1 ago. 2003. Disponível em: <http://www.ub.es/geocrit/sn/sn-146(121).htm> Acesso em: 08 jan. 10.

JANOSCHKA, Michael; GLASZE, Georg. Urbanizaciones cerradas: um modelo analítico. Ciudades. Puebla (México): Red Nacional de Investigación Urbana, n. 59, jul-set, 2003, p. 09-19.

LANTE, Ricardo Giamlourenço. A legislação, o Condomínio e o Parque em São Carlos. Presidente Prudente: FCT/UNESP, 2007 [Relatório FAPESP].

LEFEBVRE, Henri. O direito à cidade. São Paulo: Editora Moraes, 1991. Trad. Rubens Eduardo Frias.

MEUBIROUK, Hayet. La fragmentation socio-spatiale à Annaba, un paradigme de crise urbaine. GREGUM. Le Mans: Université du Maine, set, 2006. Disponível em: <http://subaru2.univ-lemans.fr/lettres/ labo/gregum/activites/colloques/sfax/axe2/mebirouk_hayet.html >. Acesso em: 12 jan. 10.

NAVEZ-BOUCHANINE, Françoise. Des villes entre fragmentation spatiale et fragmentation sociale: Une approche critique de la notion de fragmentation. In: DORIER-APPRILL, Elisabeth (dir.). Vocabulaire de la ville. Notions et références. Paris: du Temps, 2001.

SALGUEIRO, Teresa Barata. Lisboa, Periferia e Centralidades. Oieiras, Portugal: Celta Editora, 2001. SANTOS, Milton. Metrópole corporativa, fragmentada: o caso de São Paulo. São Paulo: Nobel, 1990. SCHMIDT, Margarita. Transformaciones recientes en una ciudad intermedia. El caso de Mendoza (Argentina). Encuentro de Geografos de América Latina, 9., Mérida, México: [s.n.], abr., 2003. 20p. 1 CD-ROM. SEABRA, Odette Carvalho de Lima. Territórios do uso: cotidiano e modo de vida. Cidades. Presidente Prudente: Grupo de Estudos Urbanos, v. 1, n. 2, 2004, p. 181-206

SOBARZO, Oscar. A segregação sócio-espacial em Presidente Prudente: análise dos condomínios horizontais. Presidente Prudente, 1999. 213 f. Dissertação (Mestrado em Geografia) - Faculdade de Ciências e Tecnologia, UNESP.

SOBARZO, Oscar. ; SPOSITO, Maria Encarnação Beltrão. Urbanizaciones cerradas: reflexiones y desafíos. CIUDADES. Puebla (México), Red Nacional de Investigación Urbana, n. 59, p. 37-43, jul-sept, 2003.

SOUZA, Marcelo Lopes. O desafio metropolitano: um estudo sobre a problemática sócio-espacial nas metrópoles brasileiras. Rio de Janeiro: Bertrand Brasil, 2000. 
SOUZA, Marcelo Lopes. Fobópole: o medo generalizado e a militarização da questão urbana. Rio de Janeiro: Bertrand Brasil, 2008.

SPOSITO, Maria Encarnação Beltrão. Reestruturação da cidade. In: MELO, Jayro Gonçalves (Org.). Região, cidade e poder. Presidente Prudente: GAsPERR, 1996a. p. 111-126.

SPOSITO, Maria Encarnação Beltrão. Reflexões sobre a natureza da segregação espacial nas cidades contemporâneas. Revista de Geografia. Dourados: AGB, p. 71-85, set. 1996b.

SPOSITO, Maria Encarnação Beltrão. A cidade dentro da cidade. Uma edge city em São José do Rio Preto. Scripta Nova. Revista electrónica de geografía y ciencias sociales. Barcelona: Universidad de Barcelona, n. 146(045), vol. VII, 1 ago. 2003a. Disponível em: <http://www.ub.es/geocrit/sn/sn-146(045).htm> Acesso em: 03 mai. 2010.

SPOSITO, Maria Encarnação Beltrão. Novas periferias urbanas nas cidades médias do Estado de São Paulo - Brasil. $9^{\circ}$ Encuentro de Geografos de América Latina, Mérida, México: [s.n.], abr., 2003b. 31p. 1 CD-ROM.

SPOSITO, Maria Encarnação Beltrão. Loteamentos fechados em cidades médias paulistas, Brasil. In: SPOSITO, Eliseu Savério; ; SOBARZO, Oscar (Orgs.). Cidades médias: produção do espaço urbano e regional. São Paulo: Expressão Popular, 2006. p. 175-197.

SPOSITO, Maria Encarnação Beltrão; GOES, Eda Maria; SOBARZO, Oscar. Urbanização difusa, Espaço público e (In) segurança urbana. Projeto de pesquisa, FAPESP, 2006.

SPOSITO, Maria Encarnação Beltrão; GOES, Eda Maria; SOBARZO, Oscar. Reestruturação urbana e segregação socioespacial no interior paulista. Scripta Nova. Revista electrónica de geografía y ciencias sociales. Barcelona: Universidad de Barcelona, n. 245(11), vol. XI, 1 ago. 2007. Disponível em: <http://www.ub.es/ geocrit/sn/sn-24511.htm> Acesso em: 27 mai. 2010.

VILLAÇA, Flávio. Espaço intra-urbano no Brasil. São Paulo: Studio Nobel, 2001.

ZANDONADI, Júlio Cesar. Novas centralidades e novos Habitat: caminhos para a fragmentação urbana em Marília. Presidente Prudente, 2008. 251 f. Dissertação (Mestrado em Geografia) - Faculdade de Ciências e Tecnologia, UNESP.

Trabalho enviado em fevereiro de 2012

Trabalho aceito em março de 2012 